This is the accepted manuscript of the article, which has been published in Housing Studies. http://dx.doi.org/10.1080/02673037.2019.1680813

\title{
Explaining Homelessness as a Movement Using Metaphors in European Academic Writings of Homelessness
}

\section{Introduction}

In the late 1990s, Gurney (1999a) pointed out that analogies and metaphors play an important role in constructing meanings of homeownership, which can be seen to inversely mirror the meanings of homelessness. Recurrent metaphorical expressions are, for example, that home is 'a safe haven', whereas homelessness or living on the street may at times be metaphorically depicted as 'a dead end' or 'a pile of rocks'. Metaphors are 'common linguistic devices which allow one concept or object to be explained in terms of another through cross-domain mapping' (Gurney 1999a, p. 1709; see also Ben-Amitay et al., 2015; Lakoff \& Johnson, 1980; Levitt et al., 2000). In this paper, I approach metaphors as sense-making devices that comprise and constitute meanings of homelessness, and we explore metaphors of homelessness used in European academic writings. More precisely, it is scrutinizes how authors of academic articles make sense of and conceptualize first-person experiences of homelessness using metaphors of movement. The aim is to explore how metaphors of movement circulated in academic writings portray the complex phenomenon of homelessness and are drawn upon to explain it. It is important to shed light on how such metaphors are used as part of doing and reporting (homelessness) research. As discursive expressions, metaphors construct the social reality of homelessness, suggest explanations of homelessness and imply certain expectations of homeless persons.

The decision to focus on metaphors of movement results from a preliminary data collection and analysis process. The preliminary observation was that most of the metaphors deployed in the 
scrutinized academic articles describe homelessness as a movement in different directions or to different places, e.g. in or out of homelessness (e.g. Katisko, 2015; Kostiainen, 2015). I thought this preliminary observation was worthy of further scrutiny because, as will be seen in the analysis section, the metaphors of movement are not neutral but value-laden terms: in the context of homelessness and temporary housing, movement often comprises meanings of forced transitions and limited (housing) choices (Clapham et al., 2014; Severinsen, 2013; Wiesel, 2014). The ability of metaphors used in academic discourse to capture first-person experiences or causations of homelessness needs to be critically scrutinized, as metaphors are always equivocal and can thus be interpreted in many ways. There is a risk that metaphors used in academic writings are too distant from those used by people who have had their own experiences with homelessness (e.g. Fopp, 2009).

I begin with a brief overview of previous homelessness studies, including those that concentrate on metaphorical expressions. Then, it is explained how the multistage data collection process was conducted. Next, metaphors as discursive devices and how discursive metaphor analysis is applied are described. The analysis section is based on fine-grain readings of theoretically relevant and illuminating data examples. In the analysis, it is constructed interpretation of homelessness as movement: going along, entering and exiting various 'pathways' as well as going around in 'circles' or 'breaking' the cycle. In doing so, I demonstrate various possible discursive devices for depicting and constructing homelessness in academic writings. In the end, it is concluded that it is important for homelessness and housing researchers to increase their sensitivity towards mobility as a theoretical concept (see Dufty-Jones, 2012) as well as the ways metaphorical and other discursive expressions are used in research (see also Hastings, 2001). For instance, sensitivity in writing is necessary because using metaphors to help explain the complex causes of homelessness may unintentionally result in simplifying more individualistic or structural explanations, although these two explanation formulations can be intertwined (Fitzpatrick, 2005, 2012). 


\section{Dimensions of homelessness research}

Since the 1980s, researchers have been very active and interested in homelessness research (Pleace \& Quilgars, 2003; Toro, 2007). One task of homelessness research is to critically map and evaluate the prevalence and social distribution of homelessness in different countries (e.g. Anderson \& Collins, 2014; Benjaminsen, 2016; Benjaminsen \& Bastholm Andrade, 2015; Bramley \& Fitzpatrick, 2018; Culhane \& Metraux, 1999; Edgar et al., 2007; Fitzpatrick, 2012; Toro et al., 2007). Another aim is to clarify definitions of homelessness and discuss their various aspects and implications (Anderson \& Christian, 2003; O’Neil et al., 2017; Pleace \& Quilgars, 2003). For instance, a relevant distinction has been made between short- and long-term homelessness as well as 'literally homeless', 'precariously housed', and 'at imminent risk of being homeless' (Toro, 2007). In Europe, the housingbased European Typology of Homelessness and Housing Exclusion (ETHOS) recognizes four categories of homelessness and housing exclusion: rooflessness, houselessness, insecure housing and inadequate housing (Benjaminsen, 2016; Edgar \& Meert, 2005; Fitzpatrick, 2012). Sub-groups have also been identified, such as homeless families, youth, disabled individuals and single adults (Clapham et al., 2014; Kuskoff, 2018; Mackie, 2012; Toro, 2007). Homelessness has also been described as multi-dimensional deprivation of the basic requirements for human life and dignity (Somerville, 2013).

Extensive and diverse research has been conducted on homelessness causation and experiences (Edgar et al., 2007; Fitzpatrick et al., 2013; Sosin, 2003; Stephens \& Fitzpatrick, 2007). As Benjaminsen (2016, p. 2042) summarized, 'Studies generally show that a broad range of risk factors such as mental illness, substance abuse, incarceration, institutional care in childhood, relationship 
breakdown, weak social ties, poverty and unemployment are overrepresented amongst homeless people' (see also, e.g. Culhane \& Metraux, 1999). Causes and cause-and-effect relationships in the context of homelessness should not be taken as deterministic but as contingent, complex, socially constructed and potentially expected impacts (Bramley \& Fitzpatrick, 2018; Author’s own; Williams, 2001)

Causes of homelessness are commonly categorized as individual, interpersonal and structural explanations. These different explanation formulations are often theorized as having reciprocal and contingent interconnections (Fitzpatrick, 2005, 2012). Based on individualistic accounts, long-term homelessness resonates with traumatic personal (past) experiences as well as with severe (mental) health and substance abuse problems. The risk of homelessness may also be triggered by interpersonal factors, such as domestic violence, divorce, and weak, unreliable and damaging social networks. When relying on structural explanations, it is commonly stated that homelessness implies social exclusion, poverty and low-level welfare systems (Benjaminsen \& Bastholm Andrade, 2015). Each of these explanation models comprises different views on responsibility and the individual's ability (or inability) to control his or her social circumstances. Individualistic explanations of homelessness easily blame and stigmatize the homeless person and rule out awareness of the economic-social roots of homelessness (O’Neil et al., 2017), whereas structural explanations may bypass individuals' experiences, agency and resilience (Clapham, 2003; Somerville, 2013;).

From at least the 1990s, a movement towards a 'new orthodoxy' was pursued, which combined both structural and individual factors. Subsequently, scholars (e.g. Fitzpatrick, 2005, 2012; Fitzpatrick et al., 2013) have criticized the theoretical and explanatory shortages within the new orthodoxy, especially its failure to thoroughly indicate and reflect the causal relationships between agency and structure when explaining homelessness. Clapham’s (e.g. 2005) 'housing pathways framework’ can 
be seen as one theoretical development from these discussions on the causes of homelessness over time. In a series of publications, Clapham (2002, 2003, 2004, 2005) developed the housing pathways framework based on social constructionism and Anthony Giddens' (1984) theory of structuration. This makes it possible to recognize interactional and micro-level meaning making that is embedded within wider social structures and past, present and future times (e.g. Christian et al., 2011; Mackie, 2012; Wiesel, 2014). A significant body of recent literature has developed the housing pathways framework in the context of homelessness and housing services (e.g. Christian et al., 2011; Mackie, 2012; Netto, 2011; Severinsen, 2013; Author, 2018; Skobba, 2016). Common to these publications is that they reflect individual meaning making and life courses related to housing or homelessness within societal contexts and structures.

Cultural-ethnographic homelessness studies have depicted the everyday lives and experiences of homeless persons, e.g. their struggle to break out of homelessness (see, e.g., Somerville, 2013). Discursive housing and homelessness studies (Flanagan, 2018; Gurney, 1999b; Hastings, 2001; Jacobs \& Manzi, 1996; Juhila et al., 2010; Kuskoff, 2018; Marston, 2002; O’Neil et al., 2017; Ranta \& Juhila, 2019; Author, 2018; Toft, 2014) have stressed that the ways we conceptualize and make sense of homeless persons and their experiences imply and reproduce cultural expectations related to normal housing and homes, living standards, and the idea of responsible and decent citizens. Discourses about homelessness resonate and construct the ways we perceive the causes, explanations and definitions of homelessness. They shape political rhetoric and responses to homelessness. The agendas of discursive housing and homelessness studies reveal how 'social facts' are constructed in interactions, speech and texts in different contexts. Discourse is moral-power-laden and consequential and has dynamic functions interlinked with politics and practices (Hastings, 2001; Jacobs \& Manzi, 1996; O’Neil et al., 2017; Toft, 2014). For instance, Gurney’s (1999b, p. 163) study 
explored the 'notion of power relations embodied in public and private accounts of home ownership which "normalise” it as a way of consuming housing in contemporary British society'.

\section{Metaphors in Housing and Homelessness Studies}

In addition, in previous homeless research, metaphors like 'threshold', 'staircase', 'trap', ‘double bind', 'career', 'safety nets', and 'revolving door' have been noted and utilized (Fopp, 2009; Pinkney \& Ewing, 2006, p. 61; Ranta et al., 2017). The metaphors used in academic writings affect the ways in which homelessness is depicted, perceived and understood in research. For example, they affect which measures to use to solve homelessness, and whether homelessness is depicted as a 'pathway' caused by the 'socially excluded' person's life choices and insufficient life skills or as the result of structural inequalities and a 'marketing turn' in housing policies (Jacobson \& Manzi, 1996; Marston, 2002). The first interpretation suggests that homelessness is the responsibility of the individual and should be dealt with through individualistic support measures. The second interpretation implies that homelessness is society's responsibility and the result of political decisions.

In the late 1990s, Gurney (1999a, p. 1705) outlined a 'theoretical framework in which analogies and metaphors are crucial devices in the social construction of home-ownership knowledge'. Marston (2004/2016) stressed that naming people, for instance, 'homeowners', 'homeless', 'poor' or 'socially excluded' is a significant political act, as categorizing subjects situates them in regard to social, legal and economic entitlements. For instance, 'socially excluded' represents a naturalized yet contested metaphor that informs current housing policies and practices. It also identifies various tensional discourses and metaphors, e.g. a 'customer' or 'marketing turn' to indicate policy transformation in the housing sector (Jacobson \& Manzi, 1996; Marston, 2002). In line with these earlier studies, Toft (2014, p. 783) 'analyzes the discursive strategies deployed in the linguistic production of 
homelessness and homeless persons in the context of city-level policies on urban camping in a major urban center in the USA, and outlines the ways that homeless activists contested their use in the public sphere’. Fopp’s (2009) contribution in scrutinizing metaphors in homelessness discourse resonates well with this study, as he studied the use of metaphors such as 'pathways' and 'career' in his research. Such metaphors influence the expected explanations of homelessness and the characteristics that homeless persons possess. In the analysis section adds to the existing knowledge by demonstrating how the use of metaphors, such as 'pathways' and 'circles', indicates that homelessness is to be understood as the result of (forced) movement between places, localities and people.

\section{Material: Delineating the Data Corpus}

As the rationale of this article is to scrutinize the metaphors used in academic writings on homelessness, a question emerged regarding how to comprise a suitable data corpus. I ultimately decided to use peer-reviewed articles published in the following journals with European affiliations: European Journal of Homelessness (EJH), Housing Studies (HS) and Housing, Theory and Society (HTS) during the years 2012-2016 (five years). The relatively short five-year time scale was chosen to highlight currently used metaphors of homelessness and to keep the data corpus sufficiently small in order to conduct a detailed and fine-grained analysis of the chosen data extracts. This is also why I selected only three homelessness and housing journals. After completing the data collection at the end of 2016, it was proceeded to the analysis and reporting of the results and the publication process. The chosen journals comprise articles that represent international (mostly European) and topical academic research on homelessness. They all have international editorial boards, reach and reputation but have European affiliations. EJH is published by the European Observatory of Homelessness. The current managing editors of $H S$ are both from the UK, yet the journal is published by Taylor \& Francis, an international publisher. HTS is owned by the Institute for Housing and Urban Research at Uppsala University, Sweden. It can be said that the journals are skewed towards European research 
and policy agendas in respect to homelessness. By narrowing the data search to these three journals, it can be argued that the results resonate for most European homelessness studies. This became even more evident when I accomplished the final data corpus by conducting the following process.

1. The search first employed Academic Search Premier to net all academic articles published in HTS, HS and EJH in 2012-2016 that had homelessness as one of the keywords or in the title. The data included 12 articles from HTS, 14 articles from $H S$ and 39 articles from EJH. In total, 65 articles were located.

2. Next, a preliminary data-driven search of the metaphors was conducted concerning: (a) implying experiences of homelessness and (b) categorizing persons who are homeless. This resulted in a massive matrix of homelessness-related metaphors used in each of the peerreviewed articles chosen in the first step.

3. At this preliminary stage of data collection and analysis, I found that most metaphors seemed to convey a meaning of homelessness in terms of movement. Given this insight, I decided to orient subsequent searches and concentrate the analyses on such metaphors. This narrowed the research parameters to a more defined focus. In the upcoming results section, it is analyzed metaphors of movement (based on the results of the second step) that are most commonly used in the articles to define homelessness as a pathway, route or career, as well as the less frequently used expressions of circle, cycle, circuit and circulation. This enabled us to demonstrate the differences between constructing homelessness by predominant and less frequently used metaphors of movement in the data corpus. 
4. The data corpus was then narrowed down once more by reducing the 65 homelessness articles to those concentrating on homeless persons' own experiences studied through interviews or survey data. The rationale for this approach was that it makes kit possible to capture academic metaphorical language used to conceptualize first-person experiences of homelessness as movement. Specifically, I was interested in how articles conveying first-person experiences of homelessness translated and converted such experiences into scientific language through the use of metaphors of movement. At this stage, the data corpus was narrowed down to 18 articles.

5. Using the keyword search function within each of the 18 articles, article content was screened for whether the chosen metaphor of movement ${ }^{1}$ (and its variants; see steps three and four) was present. An article was included in the final database if at least one of the metaphors appeared in that article’s text (excluding the reference section). I found 15 articles that scrutinized firstperson experiences of homelessness in European contexts and made sense of homelessness using metaphors that express movement (see the Appendix for the list of articles included in the final database).

6. The data examples displayed in the results section were chosen because they demonstrated the various ways researchers (not study informants) make sense of and conceptualize the firstperson experiences of homelessness using metaphors of movement. The data excerpts demonstrate variations in: (a) metaphors implying movement, (b) the contexts that the metaphors are used in, and (c) meanings derived and functions served in the text. The aim was to demonstrate various ways to construct and explain homelessness in academic writings.

\footnotetext{
${ }^{1}$ The career metaphor was left out at this stage because it was only mentioned in the final data in two articles (20 times in one and once in the other).
} 
Depending on the chosen metaphors, movement is directed within particular time-space contexts, and the first-person experiences of homelessness are constructed differently. The data examples imply the causes, explanations and definitions of homelessness constructed in the research. Notably, given this article's scope, limited space forced to make difficult decisions concerning the few data examples that I am able to analyze in detail in the results section. Accordingly, the data examples were approached as theoretically relevant illustrations of constructing the first-person experiences of homelessness either as 'pathways' or 'circles' in academic homelessness writings - not as a representation of academic homelessness discourse as a whole.

\section{Method: Analyzing Metaphors as Discursive Devices}

In the text metaphors are studied in the framework of discursive analysis. Although discursive approaches (see, e.g., Juhila et al., 2010; Ranta \& Juhila, 2019; Author, 2018) have been previously applied in housing and homelessness studies, I argue that the discursive analysis as well as other methods based on social constructionism are underrepresented in the field. In the discursive metaphor analysis (cf. metaphor-led discourse analysis by Cameron et al., 2009), as also in this article, metaphors are studied according to the ideas of social constructionism and discourse analysis. Social constructionism emphasizes that the social world is made reasonable through micro-level meaning making at a given time and in a specific cultural context (e.g. Berger \& Luckmann, 1967; Cameron, 2007; Cameron et al., 2009; Clapham, 2002; Fairclough, 1992). In discursive metaphor analysis, the importance of the specifics of the language-using situation where the metaphor occurs as well as the complex dynamics of real-world language are stressed (Cameron et al., 2009; Tay, 2011). For instance, as Hellsten (2005, p. 287) stated, 'The metaphor resonates widely across the contexts of use, and can therefore be expected to be fruitful in the translation of science communication.' Hence, metaphors get their meanings according to their role in (mutual) communication and to the message 
they transmit. In scientific discourses and discussions, metaphors often play a powerful role in shaping study objects and directing theoretical reasoning (Ben-Amitay et al., 2015; Brown, 2003; Hellsten, 2005).

In the following results section, discursive metaphor analysis is applied by carefully scrutinizing theoretically relevant data extracts in order to demonstrate how homelessness as a study object is constructed via expressions of movement. It thus concentrates on analyzing discursive particulars of time and space, i.e. expressions of mobility (see the second stage of the analysis below). The conducted analysis does not seek an overall presentation of the meanings of the 'pathway' and 'circle' metaphors (as there are various in shifting contexts) in the academic homelessness writings, but to show the different potential ways to construct homelessness as movement.

It was proceeded with the two-stage analysis as follows:

1) Using the results from the fifth step of the process of compiling the final data corpus, I was able to classify pathway and route as predominant metaphors (used in 15 articles a total of 354 times $)^{2}$ and circle, cycle, circuit and circulation as marginal, i.e. less utilized, metaphors (used in 14 articles a total of 30 times). ${ }^{3}$ This rough division of the metaphors of movement into two groups served as the basic structure for the analysis.

2) I scrutinized the chosen data examples for different portrayals of homelessness as movement in time and space, e.g. linear and deterministic or going back and forth. The analysis demonstrates how homelessness as movement is constructed so that it takes different

\footnotetext{
${ }^{2}$ Pathway $(\mathrm{N}=216)$; Path $(\mathrm{N}=23)$; Route $(\mathrm{N}=32), 271$ in total.

${ }^{3}$ Circle $(\mathrm{N}=7)$; Cycle $(\mathrm{N}=17)$; Circuit $(\mathrm{N}=3)$; Circulate $(\mathrm{N}=3)$, 30 in total.
} 
directions and has various explanations, triggers and actors that resonate well with previous research on the causes and explanations of homelessness (see section 'Dimensions of homelessness research'). The choice of what metaphor to use in academic writing is consequential; in our study, it translates and interprets the first-person experience of homelessness as either a 'pathway' or a 'circle'. These metaphors also trigger the use of other discursive devices that indicate transitions in time and space, which are discussed in the analysis. To make it easier to follow the analysis of the data examples, the metaphors are in italics, whereas invoked assumptions about explanations of (breaking out of) homelessness and people who are homeless are underlined.

When using a rather small data corpus and concentrating on illustrative data examples of academic writings, it is important to take caution to avoid overgeneralizations. The study reveals various discursive possibilities when making sense of what homelessness is, rather than the academic homelessness discourse as a whole.

\section{Results: Homelessness as movement}

As a general term, 'pathways' has an established, even a predominant position in housing and homelessness research, whereas 'circle' is seldom used and less reflected. By using the pathways metaphor, many authors have developed various typologies of housing and homelessness narratives (e.g. Chamberlain \& Johnson, 2013; Fitzpatrick, 2000; Author). In general, pathways refer to transitions between different housing facilities and lived experiences related to these facilities (e.g. Kras et al., 2016). At times, pathways are used in homelessness research concurrently with the career metaphor (see, e.g., May, 2000). However, pathway is also used as a distinct analytical concept within Clapham’s housing pathways framework (see ‘Dimensions of homelessness research’ above). 


\section{Predominant Metaphors: Path(way) and Route}

The first data example is from a Diebäcker et al. (2015) article, 'Parenting within Homelessness: A Qualitative Study on the Situation of Homeless Fathers and Social Work in Homeless Support Services in Vienna', which does not take the housing pathways framework (e.g. Clapham, 2005) as a starting point. From the extract below, it can be seen how various structural inequalities and health problems are constructed as triggers and explanations for moving into homelessness pathways.

Most interviewees can be described as having impaired health, with descriptions of physical and psychological symptoms varying considerably. The interplay between psychological illnesses (i.e., depression) and addiction (here, alcoholism in particular) constituted a burden for the interviewees in terms of their current lifestyle, or retrospectively. With regard to individual pathways into homelessness, the research showed that (suddenly occurring) loss of work and unemployment, material poverty and health impairments were central structural parameters of the homelessness of the interviewees (Diebäcker et al., 2015, p. 94).

The metaphor 'homelessness pathways' is constructed as a result of both individual and structural causes; however, a causal relationship between them is not distinctly constructed. Constructing both person-related and social causes and explanations of homelessness is a common feature of academic discourses on homelessness (see 'Dimensions of housing research' above). In the excerpt, various vulnerabilities are in a way 'pushing' men to move from housing to 'pathways into homelessness'. By definition, pathway suggests movement from a starting point A to an endpoint B. Homelessness pathways are culturally constructed as undesirable shifts from the 'mainstream highways' to the margins or between spaces and places located on the fringes of society (Clapham, 2005). Movement 
in time and space is also realized with such discursive devices as 'current lifestyle', 'retrospectively', and 'suddenly occurring'.

In sum, homelessness pathways are explained by internal and external forces leading 'into' homelessness, almost as deterministic 'one-way streets'. The idea of generating pathways in time is strengthened by using various expressions of time. Men’s own agency or ways of making sense of the causal relationships of their homelessness pathways are not made visible in the extract, and in this way, pathway is used as a general and generalizing metaphor. Men’s experiences are reported as one collective narrative of entering the homelessness pathway, rather than making visible the differences in first-person experiences and causal accounts.

The next data example is from Katisko’s (2015) article, ‘Homelessness among Immigrant Youth: Transitions between Inclusion and Exclusion', which operates with metaphors of paths and routes. The researcher begins by stating that 'homeless youths of immigrant background' is not a homogeneous category. Yet, the article identifies some widely shared features and life circumstances leading to youth homelessness:

The situations of interviewees were quite varied. Routes to homelessness variously involved a breakdown in the immediate social circle (primarily family), gaps in the service system or discrimination in the rental flat market. On the other hand, the movement into homelessness did not happen in one direction only, and as one risk was realized, another safety network might save the youth, at least temporarily (Katisko, 2015, p. 67). 
The metaphor of 'route' holds similar connotations concerning homelessness as 'pathways'. Routes, as well as pathways are avenues for movement-in this case, towards homelessness. However, it is recognized that 'movement into homelessness did not happen in one direction only'. Thus, homelessness is portrayed as a 'multi-way street' or a 'crossroad' with plausible 'exits', making possible to depart from homelessness, using metaphorical language, via the 'safety network' before reaching the endpoint of homelessness. However, movement out of homelessness may turn out to be just a 'side route' that eventually leads back to homelessness. Routes to homelessness comprise movement caused by others who turn homeless youths away from informal, public and market-based recourses and support.

To conclude, the idea of fragmented and emerging routes to homelessness is supported by using other space-time-related terms, such as 'breakdown', 'gaps' and 'temporarily', as well as indicating back and forth movement between homelessness and housing. These routes that come into existence when something ‘breaks down’ or fails are explained by interpersonal and structural factors (not by personal characteristics or disadvantages). As in the first data sample, causes of homelessness are reported in a way that fades homeless persons' agency and sense-making practices. This is done by using a passive and generalized writing style as well as using abstract expressions, such as 'social exclusion', 'discrimination' or 'social circle'. The next data example demonstrates how, in academic writing, it is possible to emphasize homeless persons’ own endeavours, activities, wills and wants when making sense of movement (out) of homelessness.

The final data extract of this section is from Natalier and Johnson's (2012) article, 'Housing Pathways of Young People Who Have Left Out-of-Home State Care', which does draw on Clapham’s (e.g. 2002, 2005) housing pathways framework. The excerpt is drawn from a section where the authors 
report on how many young people move on from their volatile circumstances and how the pathways people travel can and do change for the better.

Kelly’s pathway is an example of moving on. At the time of her interview, Kelly and her long-term boyfriend were about to move into a new flat after living in their current home for two years. During this period of residential stability she has been employed as a carer working with disabled people and is currently completing her university $\underline{\text { studies. }}$ The decision to move was sparked by a recent rent increase, but importantly the move is on her terms: 'I want to_pay for something nicer and get what I want out of it'. Kelly is on good but tentative terms with her biological family. She feels positive about her future (Natalier \& Johnson, 2012, pp. 85-86).

In the example, the 'pathway' metaphor emphasizes transiting from a difficult past to a better, stable and secure future. Pathway is constructed by indicating markers of normal living: good-quality housing, a heterosexual relationship and employment. The pathway is personalized in the sense that it is Kelly's route, accomplished through her efforts, activity and will; yet, causal relationships are not clearly explicated. In addition to pathway, several other discursive devices also support the idea of stability and progress in time and space: 'at the time', 'long-term', 'to move’, 'residential stability', 'currently', 'recent' and 'future'. The data example provokes images of an active, determined and responsible citizen moving in a goal-directed manner on 'highways' of normal living and housing (see Clapham, 2005). 


\section{Marginal Metaphors: Circulation, Circle, Cycle and Circuit}

In addition to making sense of homelessness as moving along a path(way) or route into or out of unstable housing or sleeping rough (see, e.g., Kostiainen, 2015), I recognized from the data corpus another metaphor of movement: circulation, circle, cycle and circuit are used to construct homelessness as orbicular movements without clear end or exit points.

The next data example is from an article titled 'Pathways through Homelessness in Helsinki', which applies various 'pathway frameworks' (Kostiainen, 2015). The following example was extracted from a sub-section titled 'Disadvantaged Homeless People’.

The group of disadvantaged homeless people consisted of three clusters, where most respondents had used homelessness services to exit but some were still homeless at the time of responding. In the first cluster, respondents ended up homeless from mainly stable housing careers in rental or owner-occupied housing. During the period of homelessness, most slept rough or with occasional acquaintances. In the second cluster, people had ended up homeless from rental housing or from dependent housing without a lease agreement of their own. During the homelessness period, most lived with friends or relatives or circulated between different friends and relatives. Respondents in the cluster of 'long-term homeless people' ended up homeless mainly from various homeless accommodation services or prison. Most slept rough during the period (Kostiainen, 2015, p. 75).

Various descriptions of movement and expressions of time, such as 'to exit', 'still homeless', 'ended up homeless', 'housing careers', and 'during the period of homelessness', are used in the excerpt 
when describing from where different sub-groups of homeless people move into homelessness and how they travel during the time of homelessness. Homelessness is constructed as an interruption of stable housing careers to move in unpredictably circular patterns in temporary housing placements. The style of writing in the aforementioned article is descriptive and distanced from the informants' ways of describing their reality of homelessness. This makes it possible to depict homelessness as passive traveling and circulating into and out of various temporal spaces of residence. Informants' agency is not made visible; rather, homelessness is approached as a population-level phenomenon that, for some groups, results in circulating movement. However, the causes and explanations are not explicitly reflected.

The next extract is from an article “'It's just like we're going around in circles and going back to the same thing ... '? The Dynamics of Women’s Unresolved Homelessness', which attempted to capture multiple transitions and changes in women's circumstances along the same timeline (Mayock et al., 2015). The excerpt is part of a section where findings concerning women's movements and agency within the context of insecure housing are summarized.

The women's accounts strongly suggest that the condition and experience of being homeless significantly impacted their decision-making and the strategies they deployed in their efforts to secure housing. Following lengthy periods of commuting between emergency homeless hostels, many appeared to avail of every possible prospect of exiting these temporary living situations. In this sense, women were acting independently but within a landscape of highly constrained choices or options. The material conditions they experienced in emergency accommodation settings, combined with the social and emotional stress associated with hostel life, were significant in pushing them towards housing options that carried risks and often served to exacerbate 
their situations. Thus, in seeking ways out of homelessness, women often entered into living situations that resulted in their ongoing and, sometimes, more acute isolation. It is perhaps important to state that, very often, women narrated their movements between living situations in quite unremarkable terms, suggesting that their transience had become part and parcel of the search for stability. In the absence of housing, residential instability therefore inadvertently became a solution for a large number. Their exits from homelessness were not enduring and often resulted in further trauma; most returned to homeless services within weeks or months and the cycle of homelessness continued (Mayock et al., 2015, p. 893).

Above, homelessness is portrayed as a cycle: circulating movement in time is captured in expressions such as 'lengthy periods', 'exiting', 'pushing them towards', 'entered into', 'ongoing', 'transience', and 'search for stability'. The cycle of homelessness is explained by unfavourable material conditions that affect women's decision making in undesirable ways: women are active actors, but they end up being victims of the exclusive and abusive housing systems on the margins. The cycle metaphor and other supporting phrases of movement depict homelessness as endlessly traveling from one undesirable place or individual to another. The reader can gain a sense of women's experiences and explaining practices; however, it is the researcher who concludes the creating forces and the nature of the cycle of homelessness.

The final example is from Ornelas et al.'s (2014) article, 'Housing First: An Ecological Approach to Promoting Community Integration', which scrutinizes life experiences during transitions from homelessness to housing and uses pathways as a general term. The excerpt demonstrates one way of constructing and explaining how to break away from the homelessness circuit. 
Having a house and an address was essential to organize participants' documentation that, in turn, allowed them to access a source of secure income. Additionally, efforts were made to link participants to mainstream health and social community services that are used by the general population. That allowed participants to break away from_the homeless services circuit, which improved community integration. Living in the community also creates more opportunities for people to participate in community life. In our study, participants reported that they started to discover their neighbourhoods and to use the local resources, like coffee shops, grocery stores, churches and leisure contexts. Some participants even started work or returned to school (Ornelas et al., 2014, pp. 48-49).

Exiting homelessness is constructed and explained as a movement away from the 'homeless services circuit' to having a regular home in the community. Conversely, homeless services are seen as constituting a circle that excludes homeless people from the community and the resources needed for sustained housing, i.e. causing homelessness. It is argued that one can break away from this circuit if one has resources and support, and is linked to mainstream housing, services and activities in the community, i.e. to culturally normal and approved traveling between public spaces such as coffee shops, schools and workplaces. This traveling is emphasized by using terms such as 'access', 'link', 'mainstream', 'break away' and 'return'. In academic writing, participants are constructed both as informants and individual actors who break out from homelessness as well as objects of the measures of the Housing First programme and as a collective entity. The crucial question about academic writing is how do we generalize without losing valuable details in individual homelessness narratives and explanation formulations? In addition, the extract raises the question of how do the movements in the community and the linking actually take place at the grassroots level by homeless persons or housing service personnel? 


\section{Conclusions}

According to the data, by using the metaphors of pathway and circle, homelessness is constructed as: inevitable, passive traveling into homelessness; fragmented and emerging routes to homelessness; active navigation between places; being trapped in a circle of insecure and isolating homelessness services; and moving decisively towards stability and normality in life. Additionally, it was found homelessness to be constructed as movement by utilizing other phrases and metaphors that allude to transitions, such as 'into', 'out', 'exit', 'seeking ways out of homelessness' or 'moving on'. Firstly, it appears from the analysis that pathway is somewhat of a 'floating' discursive device in many cases, used with a variety of meanings with only a loose similarity retained that suggests movement between locations. Often, different triggers of homelessness are recognized, but actual causal relationships between them are not clearly stated or reflected. Hence, for instance, future research on how the housing pathways framework (e.g. Clapham, 2005) is further developed as a conceptual and empirical approach in current housing and homeless research would be beneficial. There is also a call for more research on the metaphors that homeless people use themselves when constructing and explaining their first-person experiences in different circumstances and cultural contexts.

Previous research has also stated that housing and homeless studies are commonly underpinned by metaphors of movement that have almost become 'dead metaphors', i.e. so self-evident, naturalized and taken-for-granted that they are not easily recognized as contested metaphors (Fairclough, 1992, pp.194-195; Gurney, 1999). This has happened to metaphors such as 'movement', 'pathway' and 'circle', which are concepts with great potential in housing and homelessness studies if they are utilized reflexively and critically (see Clapham 2003). As such, I stress that homelessness should be theorized and scrutinized more carefully as a mobility-based phenomenon in future research, using 
Wisel's (2014) 'mobility-based disadvantage' expression or Dufty-Jones (2012) notion of the 'politics of mobility'. Dufty-Jones (2012) and Wisel (2014) address the potential of homelessness and housing studies to engage more closely with recent theorizations of mobility, i.e. 'mobility turn' in social sciences, which could be an important development.

Because of the 'discursive power' inherent in metaphors and other discursive devices (Fairclough, 1992, pp.194-195), researchers have an ethical and moral duty to be mindful of how they choose and utilize metaphors, as well as ensuring that they properly contextualize these metaphors. Hastings (2001, p. 138) also addressed the need for more 'reflexivity about how language is used in research'. Reflexivity is needed because language choices convey various understandings of the causation (and solutions) of homelessness. In that way, they also distribute responsibility and assign blame differently to the various stakeholders in the field.

\section{References}

Anderson, I. \& Christian, J. (2003) Causes of homelessness in the UK: A dynamic analysis, Journal of Community and Applied Social Psychology, 13(2), pp. 105-118.

Anderson, J. T. \& Collins, D. (2014) Prevalence and causes of urban homelessness among indigenous peoples: A three-country scoping review, Housing Studies, 29(7), pp. 959-976.

Ben-Amitay, G., Buchbinder, E. \& Toren, P. (2015) Understanding sexual revictimization of women through metaphors: A qualitative research, Journal of Aggression, Maltreatment \& Trauma, 24(8), pp. 914-931.

Benjaminsen, L. (2016) Homelessness in a Scandinavian welfare state: The risk of shelter use in the Danish adult population, Urban Studies, 53(10), pp. 2041-2063.

Benjaminsen, L. \& Bastholm Andrade, S. (2015) Testing a typology of homelessness across welfare regimes: Shelter use in Denmark and the USA, Housing Studies, 30(6), pp. 858-876.

Berger P. L. \& Luckmann, T. (1967) The Social Construction of Reality. (Garden City, NY: Doubleday). 
Bramley, G. \& Fitzpatrick, S. (2017) Homelessness in the UK: who is most at risk? Housing Studies. Published online: 01 Jul 2017.

Brown, T.L. (2003) Making Truth: Metaphor in Science (Urbana, US: University of Illinois Press).

Cameron, L. J. (2007) Patterns of metaphor use in reconciliation talk, Discourse \& Society, 18(2), pp. 197-222.

Cameron, L., Maslen, R., Todd, Z., Maule, J., Stratton, P. \& Stanley, N. (2009) The discourse dynamics approach to metaphor and metaphor-led discourse analysis, Metaphor \& Symbol, 24(2), pp.63-89.

Chamberlain, C., \& G. Johnson (2013) Pathways into Adult Homelessness, Journal of Sociology, 49(1), pp. 60-77.

Christian, J., Clapham, D. \& Abrams, D. (2011) Exploring homeless people’s use of outreach services: Applying a social psychological perspective, Housing Studies, 26 (5), pp. 681-699.

Clapham, D. (2002) Housing pathways: A postmodern analytical framework, Housing, Theory \& Society, 19(2), pp. 57-68.

Clapham, D. (2003) Pathways approaches to homelessness research, The Journal of Community and Applied Social Psychology, 13(2), pp. 119-127.

Clapham, D. (2005) The Meaning of Housing: A Pathways Approach (Bristol, UK: Policy Press).

Clapham, D., Mackie, P., Orford, S., Thomas, I. \& Buckley, K. (2014) The housing pathways of young people in the UK, Environment and Planning, 46(8), pp. 2016-2031.

Culhane, D. \& Metraux, S. (1999) Assessing relative risk for homeless shelter usage in New York City and Philadelphia, Population Research and Policy Review, 18(3), pp. 219-236.

Dufty-Jones, R. (2012) Moving home: theorizing housing within a politics of mobility, Housing, Theory and Society, 29(2), pp. 207-222.

Denvall, V. (2017) Evaluating homelessness - a comparative analysis of top 10 articles from the US and Europe, European Journal of Social Work, 20(5), pp. 724-740.

Edgar, B. \& Meert, H. (2005) Fourth Review of Statistics on Homelessness in Europe. The ETHOS Definition of Homelessness (Brussels: FEANTSA). Available at:

https://www.feantsaresearch.org/en/other-observatory-publications/2005/11/23/fourth-review-ofstatistics-on-homelessness-in-europe-2005?bcParent=766

Edgar W., Harrison, M. \& Watson, P. \& Busch-Geertsema, V. (2007) Measurement of Homelessness at European Union Level (Brussels: European Commission, DG Employment, Social Affairs and Equal Opportunities). Available at https://ec.europa.eu/employment_social/social_inclusion/docs/2007/study_homelessness_en.pdf 
Fairclough, N. (1992) Discourse and Social Change (Cambridge, UK: Polity).

Fitzpatrick, S. (2000) Young Homeless People. Basingstoke: Macmillan.

Fitzpatrick, S. (2005) Explaining homelessness: A critical realist perspective, Housing, Theory \& Society, 22(1), pp. 1-17.

Fitzpatrick, S. (2012) Homelessness, in: D. Clapham, W. Clark \& K. Gibb (Eds) The Sage Handbook of Housing Studies, pp. 359-378 (London: Sage).

Fitzpatrick, S., Bramley, G. \& Johnsen, S. (2013) Pathways into multiple exclusion homelessness in seven UK cities, Urban Studies, 50(1), pp. 148-168.

Flanagan, K. (2018) 'Problem families' in public housing: discourse, commentary and (dis)order, Housing Studies, 33(5), pp. 684-707.

Fopp, R. (2009) Metaphors in homelessness discourse and research: Exploring 'pathways', 'careers' and 'safety nets', Housing, Theory \& Society, 26(4), pp. 271-291.

Gurney, G. (1999a) Lowering the drawbridge: A case study of analogy and metaphor in the social construction of homeownership, Urban Studies, 36(10), pp. 1705-1722.

Gurney, G. (1999b) Pride and prejudice: Discourses of normalisation in public and private accounts of home ownership, Housing Studies, 14(2), pp. 163-183.

Hastings, A. (2000) Discourse analysis: What does It offer housing studies?, Housing, Theory \& Society,17(3), pp. 131-139.

Hellsten, I. (2005) From sequencing to annotating: Extending the metaphor of the book of life from genetics to genomics, New Genetics and Society, 24(3), pp. 283-97.

Jacobs, K. \& Manzi, T. (1996) Discourse and policy change: the significance of language for housing research, Housing Studies, 11(4), pp. 543-560.

Jacobs, K., Kemeny, J. \& Manzi, T. (2004) Introduction, in: K. Jacobs, J. Kemeny \& T. Manzi (Eds) Social Constructionism in Housing Research, pp. 1-13 (Aldershot, UK: Ashgate).

Juhila, K., Hall, C. \& Raitakari, S. (2010) Accounting for the clients' troublesome behaviour in a supported housing unit: Blames, excuses and responsibility in Professionals' Talk, Journal of Social Work, 10(1), pp. 59-79.

Katisko, M. (2015) Homelessness among immigrant youth: Transitions between inclusion and exclusion, European Journal of Homelessness, 9(1), pp. 61-76.

Kostiainen, E. (2015) Pathways through homelessness in Helsinki, European Journal of Homelessness, 9(2), pp. 63-86. 
Kras, K., Pleggenkuhle, R. \& B. M. Huebner (2016) A new way of doing time on the outside: Sex offenders' pathways in and out of a transitional housing facility, International Journal of Offender Therapy and Comparative Criminology, 60(5), pp. 512-534.

Kuskoff, E. (2018) The importance of discourse in homelessness policy for young people: an Australian perspective, Journal of Youth Studies, 21(3), pp. 376-390.

Lakoff, G. \& Johnson, M. (1980) Metaphors We Live By (Chicago, US: University of Chicago Press).

Mackie, P.K. (2012) Housing pathways of disabled young people: Evidence for policy and practice, Housing Studies, 27(6), pp. 805-821.

Marston, G. (2002) Critical discourse analysis and policy-orientated housing research, Housing, Theory and Society, 19(2), pp. 82-91.

Marston, G. (2004/2016) Constructing the meaning of social exclusion as a policy metaphor, in: K. Jacobs, J. Kemeny \& T. Manzi (Eds) Social Constructionism in Housing Research, pp. 71-92 (Aldershot,UK:Ashgate/Routlege).

May, J. (2000) Housing histories and homelessness careers: A biographical approach, Housing Studies, 15(4), pp. 613-638.

Natalier, K. \& Johnson, G. (2012) Housing pathways of young people who have left out-of-home state care, Housing, Theory \& Society, 29(1), pp. 75-91.

Netto, G. (2011) Identity negotiations, pathways to housing and "place”: The experience of refugees in Glasgow, Housing, Theory and Society, 28 (2), pp. 123-143.

Ornelas, J., Paulo M., Zilhao, M. T. \& Duarte, T. (2014) Housing first: An ecological approach to promoting community integration, European Journal of Homelessness, 8(1), pp. 29-56.

Pinkney, S. \& Ewing, S. (2006), The Costs and Pathways of Homelessness: Developing Policyrelevant Economic Analyses for the Australian Homelessness Service System (Department of Families, Community Services and Indigenous Affairs, Canberra).

O’Neil, M., Gerstein Pineau, M., Kendall-Taylor, N. \&Volmert, D., Stevens, A. (2017) Finding a Better Frame: How to Create More Effective Messages on Homelessness in the United Kingdom. FrameWorksInstitute. Available at: https://www.crisis.org.uk/ending-homelessness/homelessnessknowledge-hub/services-and-interventions/finding-a-better-frame-how-to-create-more-effectivemessages-on-homelessness-in-the-united-kingdom-2017/

Pleace, N. \& Quilgars, D. (2003) Led rather than leading? Research on homelessness in Britain, Journal of Community and Applied Social Psychology,13(2), pp. 187-196.

Ranta, J. \& Juhila, K. (2019) Constructing sense of home in floating support for people using drugs. Qualitative Social Work. First published 02 May 2019.https://doi.org/10.1177/1473325019847262 
Ranta, J., Raitakari, S. \& Juhila, K. (2017) Vastuuneuvottelut huumeidenkäyttäjien asunnottomuuden toiminnallisissa loukuissa [Negotiating Responsibilities in the Double Binds of Drug Users' Homelessness], Yhteiskuntapolitiikka, 82(2), pp. 43-53.

Severinsen, C. A. 2013. Housing pathways of camping ground residents in New Zealand, Housing Studies, 28 (1), pp. 74-94.

Skobba, K. (2016) Exploring the housing pathways of low-income women: a biographical approach, Housing, Theory and Society, 33 (1): 41-58.

Somerville (2013) Understanding Homelessness, Housing, Theory and Society, 30(4), pp. 384-415.

Sosin, M. R. (2003) Explaining adult homelessness in the U.S. by stratification or situation, The Journal of Community and Applied Social Psychology, 13(2), pp. 91-104.

Stephens, M. \& Fitzpatrick, S. (2007) Welfare regimes, housing systems and homelessness: How are they linked?, European Journal of Homelessness, 1, pp. 201-212.

Tay, D. (2011) Therapy is a journey as a discourse metaphor, Discourse Studies, 13(1), pp. 47-68.

Toro, P. A. (2007) Toward an International Understanding of Homelessness, Journal of Social Issues, 63(3), pp. 461-481.

Toro, P. A., Tompsett, C. J., Philippot, P., Nachtergael, H., Galand, B., Schlienz, N., Stammel, N., Yabar, Y., Blume, M., MacKay, L. \& Harbey, K. (2007) Homelessness in Europe and the United States: A comparison of prevalence and public opinion, Journal of Social Issues, 63(3), pp. 505-52.

Toft, A. (2014) Contesting the deviant other: Discursive strategies for the production of homeless subjectivities, Discourse \& Society, 25(6), pp.783-809.

Williams, M. (2001) Complexity, probability and causation: Implications for homelessness research, Journal of Social Issues, 1(2). Available at http://www.whb.co.uk/socialissues/mv.htm

Wiesel, I. (2014) Mobilities of disadvantage: The housing pathways of low-income Australians, Urban Studies, 51(2), pp. 319-334. 


\section{APPENDIX}

\section{FINAL DATABASE}

\section{European Journal of Homelessness $(\mathrm{N}=8)$}

Bernad, R., Yuncal, R. \& Panadero, S. (2016) Introducing the housing first model in Spain: First results of the habitat programme, European Journal of Homelessness, 10(1), pp. 53-82.

Diebäcker, M., Arhant, Y. \& Harner, R. (2015) Parenting within homelessness: A qualitative study on the situation of homeless fathers and social work in homeless support services in Vienna, European Journal of Homelessness, 9(2), pp. 87-111.

Fitzpatrick, S., Johnsen, S. \& Bramley, G. (2012) Multiple exclusion homelessness amongst migrants in the UK, European Journal of Homelessness, 6(1), pp. 31-58.

Katisko, M. (2015) Homelessness among immigrant youth: Transitions between inclusion and exclusion, European Journal of Homelessness, 9(1), pp. 61-76.

Kostiainen, E. (2015) Pathways through homelessness in Helsinki, European Journal of Homelessness, 9(2), pp. 63-86.

Mayock, P., Sheridan, S. \& Parker, S. (2012) Migrant women and homelessness: The role of gender-based violence, European Journal of Homelessness, 6(1), pp. 59-82.

Nordfeldt, M. (2012) A Dynamic perspective on homelessness: Homeless families in Stockholm, European Journal of Homelessness, 6(1), pp. 105-123.

Ornelas, J., Martins, P., Zilhão, M. T. \& Duarte, T. (2014) Housing first: An ecological approach to promoting community integration, European Journal of Homelessness, 8(1), pp. 29-56.

Housing Studies $(\mathrm{N}=3)$ 
Mackie, P.K. (2012) Housing pathways of disabled young people: Evidence for policy and practice, Housing Studies, 27(6), pp. 805-821.

Mayock, P., Sheridan, S. \& Parker, S. (2015) 'It's just like we're going around in circles and going back to the same thing ...': The dynamics of women's unresolved homelessness, Housing Studies, 30(6), pp. 877-900.

Whiteford, M. (2013) New labour, street homelessness and social exclusion: A defaulted promissory note?, Housing Studies, 28(1), pp 10-32.

\section{Housing, Theory and Society $(\mathrm{N}=4)$}

Natalier, K. \& Johnson, G. (2012) Housing pathways of young people who have left put-of-home state care, Housing, Theory \& Society, 29(1), pp. 75-91.

Severinsen, C. A. \& Howden-Chapman, P. (2014) The problem and politics of temporary housing, Housing, Theory \& Society, 31(2), pp. 125-147.

Sharam, A. \& Hulse, K. (2014) Understanding the nexus between poverty and homelessness:

Relational poverty analysis of families experiencing homelessness in Australia, Housing, Theory \& Society, 31(3), pp. 294-309.

Parsell, C. \& Parsell, M. (2012) Homelessness as a choice, Housing, Theory \& Society, 29(4), pp. 420-434. 